\title{
Teaching experience of final clinical practice by Chinese pharmacy major students based on the method combined by the learning-guiding teaching method and CAl teaching method
}

\author{
Shougang Wang \\ Beihua university affiliated hospital (First Clinic Medical College), 132011, Jilin, China
}

\begin{abstract}
On the gradual implementation of the new medical education reform and thoroughly applying the Educational Development Plan and the Health Care System Reform, the teaching mode of medical discipline will be changed gradually by following the law of medical education and meeting the need to boost the medical education reform. Meanwhile, the changing life-style prompts the traditional dispensing mode for Chinese traditional medicine to various modes. This changing put forward higher requirement for medicine- related professionals During the process of Chinese medicine teaching, the only method which can fulfill the new need for graduates of Chinese medicine and qualified medicine personals is to change the traditional teaching mode to the new ones which can arose the enthusiasm of working and learning by the traditional medicine students.
\end{abstract}

\section{Introduction}

Among the courses of the medicine discipline, Chinese pharmacy is relatively strong application and requires high practice ability. Thus, during its learning process, practice ability should be got more attentions based on strengthen the theory study[1]. Consequently, the graduates from the Chinese pharmacy can enhance their ability of linking theory to practice and working ability. In the course of learning period, final clinical practice is one of the important stage and measure to perfect the graduates' theory and practice abilities.

Learning-guiding teaching method is guided by the teacher, learn and practice by students independently. This method treats students as the learning subject, makes them gain knowledge intelligently and actively. Basing on encouraging students' autonomy penetrates the correct direction given by the teacher, which can make both teachers and students do their best to get what they deserve.

Combining CAI (Computer Aided Instruction) method with the Learning-guiding teaching method is taken during final clinical practice.

\section{The implementing form of the teaching method combining learning- guiding method with CAl teaching method}

The main implementing form including as follows:

Firstly, students learn independently. General speaking, in the process of final clinical practice, all 
internship units are relatively busy, therefore, the instructors usually cannot explain agents one by one. In order to get significant practice effect and guarantee the pharmacy to run normally, students are required to recognize agents by themselves. Thus, students will recognize the agents according to their own interests and speed, as a result of which they could learn freely and independently. To some extent, their practice interests are motivated.

Meanwhile, during the process of their final clinical practice, they will go through every step of dosage. Such experience can make them have further understanding of agents and the contradiction during dispensing medicine. Then when the students return home, they can do further study by using CAI. However, this process will lead to their unsystematic learning about the pharmaceutical knowledge after they graduate.

According to the graduates who have poor learning abilities, their learning effect will be declined a lot. Besides this, without the real-time guiding by teachers, students will be lack of the further understanding about some knowledge.

Secondly, students do focus learning. Right now, due to university's expanding their enrollment year by year, the number of graduates from Chinese pharmacy raises every year. In the process of final clinical practice, the space of the pharmacy is limited, which cannot fulfill all students practice at the same time. Hence, teachers could use the samples after collecting them. This teaching way makes students contact the real agents by themselves.

Meanwhile, teachers could apply the CAI method to teach by producing software after their data collection. Generally speaking, firstly our college will use the way of CAI to help the students to gain some understanding of the agents and secondly teach by samples, by which we can gain comparative ideal practice effect.

Thirdly, students do integrative study. In recent year, our college adopts both learning-guiding teaching method and CAI method to direct the final clinical practice. First, CAI teching method or sample teaching is used to students' focused learning, the purpose of which is to help students to understand the sharp, smell and the application site of the agents. And then, according to pharmacy's the rule of time sequence, we will choose the time for students to take part in the practice. Students who practice with problems are highly motivated and have better learning effect[2].

\section{The process of combining the learning-guiding teaching method with CAl.}

The process of combining the learning-guiding teaching method with CAI includes the key points as follows:

Firstly, a proper plan is drawn up. Before teaching, teachers draw a teaching plan according to the reality of the pharmacy, as well as the requirement made by Education Department and university. The teaching plan usually includes following content: first, the average level of theory and practice by undergraduates; second, to make sure the purposes and targets of the clinical practice by the reality of the pharmacy and the knowledge students have gained; third, to choose the teaching method scientifically by established goal and established target; forth, the effect of the clinical practice is evaluated by students' practice performance and their realities during and after their clinical practice

Secondly, CAI software is produced. CAI software includes many contents, of which difficult and important points are emphasized, make students get a deep understood reasonably. CAI software usually subdivides the teaching contents into general chapter and sub-chapters. General chapter concludes a general description about the history, origin and compatibility of compatibility etc. Every sub-chapter describes in detail about agents due to their different effect, such as fending off the chill, hemostasis, tonifying qi and so on. After this, agents are introduced one by one; for instance, lucid ganoderma is used for bad sleeping and purslane is applied for abdominal paining and diarrhea.

Thirdly, students are trained before practice. Relatively speaking, it is so different from practice and learning in class, for which careful training before practice is necessary. The training content includes the rules of the pharmacy, the notes during practice and the importance of pharmacy dispensing work, which can help them to practice carefully and have clear understanding for the work 
after graduation.

Fourthly, teachers are arranged reasonably. The choice of the teacher is in relation the effect of clinical practice. The teacher is chosen according to the following standards; first, the teacher has systematic theory knowledge and is rich in it, as well as does well in teaching; second, the teacher should do practice work seriously and explains the teaching points carefully and patiently; third, the teacher should be expressive, which can solve the problems during students' practice and learning and communicate with pharmacy well.; forth, the teacher should have advanced thoughts and accepts the new teaching pattern. They can also have a deeper understand on the syllabus and hold the practice direction exactly.

\section{The combination of learning-guiding teaching method and CAl teaching method's implement conclusion}

The using of the combination of learning-guiding teaching method and CAI teaching method's implement conclusion including the following:

First, in the process of practice teaching, the principle of "accordance of their aptitude" should be uphold, according to the graduates' interest, to master the theoretical knowledge level, practice ability, arrange content of the internship Reasonably. For example, for graduates who interested in pharmacological knowledge, can make them help pharmacy staff to do relevant experiments of pharmacological knowledge. In this way, we can maximum limit arouse graduate internship enthusiasm; significantly improve the effect of practice.

Second, during the internship, the teacher should base on graduate internship differences in content, targeted to guide the graduates to topic selection. During the period of topic selection, graduates can according to their own interests and hobbies, choose the study of pharmacological knowledge, or the study of the relevant components of agents, etc[3].

Third, in the process of practice, the teacher should encourage graduates to consult the relevant materials and the use of CAI courseware for learning; the related experimental materials were prepared as while. At this time, teacher should guide the graduates reasonably and teach them how to prepare the materials for the experience. When materials is prepared, teacher should guide the graduates to do the experience for helping them understand the important and difficult point, enhance their hand-working ability and encourage then operate independently as while.

\section{Conclusions}

Graduation practice teaching will play a practical and theoretical verification and an important role to medical students, the teaching quality of this stage will be directly related to the students majoring in pharmacy can become the target of qualified clinicians, and lay a solid foundation for students' future clinical work [4].

All in all, graduation internship is the last station of the traditional Chinese medicine learning process, and is also an important transition before the real work, is also the key to improve the ability of graduates to integrate theory with practice. In our college, through the summary of past practice and study of the new teaching mode, is committed to improve the effect of the internship, graduates for the future of the study and life lay the solid foundation.

\section{References}

1. Li XiangHong, Liu LiPing, Liang GuangRong. Research of The combination of learning-guiding teaching method and CAI teaching method during chinese medicine teaching [J]. Guide of China Medicine, 2012(06).

2. Wang MingJun, Cui Ying, Feng ZhiYi. Chinese materia medica graduate practice teaching experience [J]. China's modern distance education of Chinese medicine, 2011(11). 
3. Li YueLan, Hong Yin, Song JieMin. practice and thinking in learning-guiding teaching method in teaching of Chinese materia medica [J] . China's modern distance education of Chinese medicine, 2010(13).

4. Shutao, Liangyuan, Wenbinzhang, Boqingmao. Medical students in clinical practice teaching the investigation of the problem[J]. Medicine and society 2008(01). 